\title{
O DEPARTAMENTO DE ESTILO NA WILLYS OVERLAND DO BRASIL E SEU PIONEIRISMO NA INDÚSTRIA AUTOMOTIVA BRASILEIRA
}

\section{Marcia Barana}

Mestranda em Design, PPGDesign-UNESP

m_barana@hotmail.com

Marcos da Costa Braga

FAU -Universidade de São Paulo

bragamcb@yahoo.com.br

Paula da Cruz Landim

PPGDesign-UNESP

paula@faac.unesp.br

Resumo: O presente trabalho registra e investiga através da análise de referências bibliográficas e entrevistas, a implantação do Departamento de Estilo na Willys Overland, o primeiro do gênero na indústria automotiva instalada no Brasil.

Palavras-chave: Design, História do Design, Design no Brasil.

Abstract: This paper shows though an analysis and investigation of bibliography and interviews, the implementation of the first Design Department in automotive industry in Brazil, Willys Overland Design Department.

Keywords: Design, Design History, Design in Brazil. 


\section{INTRODUÇÃO}

Diante de uma origem marcada pela cópia de produtos importados como principal prática na implantação de produtos industriais no Brasil, nos parece relevante destacar uma empresa que foi pioneira em pensar um projeto próprio. A indústria automotiva ao se instalar no país, apesar de estar atrelada ao desenvolvimento de produtos no exterior, inicia suas atividades primeiramente vendendo automóveis completamente importados, depois passa a montar somente estes veículos com peças importadas, e mais adiante promove a nacionalização da produção de algumas peças para em fase subseqüente, e finalmente desenvolver não somente peças e componentes, mas também desenvolver alguns de seus projetos em solo brasileiro.

Com uma lente que procura observar o pioneirismo no desenvolvimento de produtos de transporte no Brasil, resgatamos para a historiografia do design por meio de um breve relato sobre a 'primeira empresa automobilística a construir uma área de design no país, denominada na época "Departamento de Estilo"' (PIANCASTELLI apud ONO, 2006, p. 156-157), assim como era chamado na época, e pioneira na produção do primeiro carro $100 \%$ "brasileiro" como entendido por Ono, (2006, p. 159) em uma grande indústria.

Nosso período de estudo compreende particularmente da década de 1950, quando as nacionalizações da produção se iniciaram nesta área, até a década de 1970, quando teremos alguns exemplos de automóveis desenvolvidos no Brasil.

Destacamos na implantação desse Departamento de 'Estilo', a figura de Roberto Mauro Araújo, Gerente Executivo do Departamento de Design. Destacamos sua liderança dentro da Willys, a repercussão das atividades do Departamento de Estilo na mídia e também sua influência no estabelecimento do Design no Brasil como campo profissional. Aqui vale falar do uso da palavra "Estilo", visto que no momento da implantação dessa indústria no país, era dessa maneira que a atividade de projeto era intitulada e seu agente era chamado de "estilista".

\section{DESENVOLVIMENTO}

A abordagem para este estudo adveio de um olhar pelo viés da Micro-História (BARROS, 2007) onde se delimita o objeto de estudo em recortes temporais e conjunturais que possibilitem uma redução na escala de observação desse objeto em meio à sociedade na qual está inserido. Observamos de aspectos do ambiente de trabalho do Departamento de Estilo até aspectos do contexto social e econômico, considerados parte da conjuntura histórica em torno do desenvolvimento do primeiro carro 100\% "brasileiro" feito dentro de uma grande montadora estrangeira aqui instalada. Focamos desde o inicio das atividades da Willys no Brasil até seus desdobramentos no começo dos anos 1970.

As fontes impressas foram publicações especializadas, bibliografia sobre a história do automóvel nesta época (1950 - 1965), e trabalhos acadêmicos. Realizamos ainda entrevistas e conversas, baseadas nos procedimentos da História Oral (ALBERTI, 2005), com profissionais que acompanharam com certa distância na época ou que estiveram inseridos neste processo da implantação do Departamento de Estilo da Willys Overland.

Acredita-se que mapear não somente o momento, mas também a energia e o desejo da realização de projetos nacionais, mais apropriados ao nosso modo de vida, 
clima e condições de rodagem, foram um caminho para afirmar uma condição brasileira mais ativa com relação ao desenvolvimento de produtos.

Buscamos referências bibliográficas partindo inicialmente do trabalho de Habara (2006) e também da obra de Nascimento (2011), além de conversas com dois pioneiros do Design de automóveis no Brasil: Ari Antonio da Rocha, autor do carro Aruanda possui grande conhecimento e convívio com os personagens em estudo, e Antonio A. De Mitry, profissional que atuou no Departamento de Estilo da Willys Overland, de 1958 a 1962. Registramos o gentil auxílio nos contatos e nas informações do Professor Auresnede Pires Stephan.

Além das referências acima citadas, destaca-se como importante fonte sobre o período a Revista Quatro Rodas, da Editora Abril, que servirá de fio condutor e para a investigação das atividades deste Departamento. Temos ainda a tese de Doutorado de Maristela Mitssuko Ono oferecendo dados complementares do design no campo do automobilismo em geral deste mesmo período.

\section{A PRIMEIRA APARIÇÃO DO VEÍCULO E A IMPLANTAÇÃO DAS PRIMEIRAS MONTADORAS NO BRASIL}

Relata-se que a primeira aparição de um veículo no Brasil foi em 1893 na Rua Direita em São Paulo (SP). O veículo era conduzido por Henrique Dumont, acompanhado do irmão, Alberto Santos Dumont. "O veículo era aberto, com quatro rodas de borracha, parecendo uma carruagem. Era um Peugeot importado da França que fazia seu primeiro passeio do Bairro dos Campos Elíseos até o centro da cidade". (NASCIMENTO, 2011, p. 11).

Desde este momento, famílias abastadas começam a importar veículos prontos e em 1919 ocorre à implantação da Ford no Brasil (com um escritório e a primeira linha de montagem). Com este fato os veículos começam a ser montados no Brasil, sendo esta a pioneira no Brasil com o Ford Bigode (Cf. NASCIMENTO, Paulo César do. Biografia do automóvel brasileiro: o design das multinacionais, 2011. p. 12).

A General Motors inicia suas operações no Brasil em 1925, segunda a se instalar no país, montando seus veículos no Bairro do Ipiranga em São Paulo e em 1930 instalou sua fábrica em São Caetano do Sul (SP). (Cf. NASCIMENTO, Paulo César do. Biografia do automóvel brasileiro: o design das multinacionais, 2011, p. 25). Vale lembrar que a montagem de veículos se inicia no Brasil, primeiramente recebendo os componentes de outras regiões para então serem somente montados aqui.

A Willys Overland só viria a se instalar no Brasil em 1952, mas mesmo que posteriormente, conseguiu marcar a história do automóvel no Brasil.

Há controvérsias sobre o primeiro veículo fabricado no Brasil, mas seguem abaixo alguns dados para orientação:

Setembro de 1956 - Romi-Isetta, feita pela Máquinas Agrícolas Romi, em Santa Bárbara D'Oeste. Na verdade este veículo é um mini-carro desenhado na Itália com espaço para somente duas pessoas e abertura frontal (Cf. NASCIMENTO, Paulo César do. Biografia do automóvel brasileiro: o design das multinacionais, 2011, p. 17).

Novembro de 1956 - Perua DKW- Vemag, feita em São Paulo pela VEMAG Veículos e Máquinas agrícolas S. A.. Neste caso com espaço para 5 pessoas e 2 portas (o que é conceituado como carro pelo GEIA - Grupo Executivo da Indústria Automobilística, criado em 1956) Cf. NASCIMENTO, Paulo César do. Biografia do automóvel brasileiro: o design das multinacionais, 2011, p. 17 - 18). 
Se incluir o segmento de utilitários ou comerciais leves, ainda teremos em 1954, o Jeep Willys, fabricado pela Willys Overland do Brasil (Cf. NASCIMENTO, Paulo César do. Biografia do automóvel brasileiro: o design das multinacionais, 2011, p. 18).

\section{DO HISTÓRICO DA WILLYS OVERLAND E SUA IMPLANTAÇÃO NO BRASIL}

$1907-1952$

A Willys Overland surgiu em 1907, Indianápolis, Estados Unidos, quando o empresário e presidente da American Motor Car Sales, John North Willys compra a Overland Automobile Company.

Seu primeiro automóvel surgiu em 1909 e em 1940, durante a Segunda Guerra Mundial, a Willys Overland apresenta o General Purpose Vehicle, destinado às Forças Armadas dos Estados Unidos e que mais tarde ficaria conhecido como Jeep (General Purpose). O projeto foi iniciado em 1950, e em 1952 foram apresentados os modelos Lark, Wing, Ace e Eagle ao mercado americano.

O mercado americano ainda via seus veículos como compactos e mediante suas incertezas, a Willys Overland do Brasil S. A. é fundada em 26 de abril de 1952, em São Bernardo do Campo - SP. (Cf. CARLOS, Luis. Site Mundo Automotivo, 2012, 21 de novembro).

No Brasil, segundo a Revista Quatro Rodas, a Willys Overland:

"participou desde os primeiros momentos do plano nacional da indústria automobilística. A área atual ocupada pela fábrica, em São Bernardo do Campo, é de 478.027,12 m².. De 1952 a 1959, o capital social passou de 50 milhões para 5.610 milhões de cruzeiros, o que possibilita também a Willys ser incluída entre as 10 maiores sociedades anônimas do Brasil. A 31 de março passado (no caso 1959), a fábrica estava empregando 5.729 pessoas. Além do Aero-Willys e do Dauphine, o modêlo (grafia do original) Renault, a Willys Overland do Brasil produz o Jeep (produção de 1956 até 1959: 38.797 unidades) e a Rural (produção de 1957 até 1959: 10.094 unidades), ... No momento a fábrica tem uma capacidade de produção de 60 mil veículos por ano." (QUATRO RODAS, 1960. n. 2, p. 9)

Em 1956 com o Plano de Metas de Juscelino Kubitschek, segundo relato de Eduardo Burgos, funcionário da Ford, em entrevista a André Fiori, "Era um clima de euforia. Houve uma confiança crescente no automóvel nacional". (FIORI, 2006, n. 556, p. 162). O início do governo de JK traz otimismo e sentido de nacionalismo. O governo de caráter desenvolvimentista incentivou a total nacionalização de produtos automotivos. Porém, observamos que este incentivo estava centrado na produção e não no projeto, o que contribuiu inicialmente para a pouca absorção de mão de obra local de designers por parte das grandes montadoras.

Entre 1958 e 1959, a indústria automotiva brasileira viu um grande esforço no sentido de construir o carro produzido nacionalmente. Em 1958 há o lançamento do DKV-Vemag com um índice de nacionalização $95,6 \%$ da produção de seus componentes. Em 1959 ainda houve os lançamentos do Sedan Volkswagen (Fusca), com nacionalização da produção de até $90,95 \%$, o Dauphine, Renault fabricado pela Willys com nacionalização em 70,22\%, e o Simca, com nacionalização de 67,65\% 
(QUATRO RODAS, 1960, n. 2. p. 7). O GEIA tinha como regra que um veículo para ser considerado nacional teria que ter $60 \%$ de sua produção feita no Brasil.

Claro que não é descartado que a maioria das fábricas instaladas até este momento era de origem estrangeira e os veículos ainda não eram 100 \% nacionais, pois seus projetos eram feitos no exterior. Em muitos momentos quando acompanhamos na mídia impressa, no caso a Revista Quatro Rodas, o índice de nacionalização da produção é bastante divulgado.

\section{OS PRINCIPAIS LANÇAMENTOS DA WILLYS OVERLAND DO BRASIL S.A. 1960 - 1972.}

A Willys Overland do Brasil S. A. iniciou suas atividades montando o Jeep Willys em 1954 (aqui denominado Jeep Universal). O modelo foi bem aceito, visto que era bem apropriado às condições de estradas nesta época, ainda bastante precárias. Após sua instalação no Brasil, se associa a Renault para a fabricação do Dauphine (sob licença), carro de origem francesa que também foi introduzido no mercado brasileiro.

A Willys já importava o Aero 1955 americano e em 25 de março de 1960 lança o Aero-Willys no Brasil que tinha $85,34 \%$, de nacionalização em sua fabricação. (QUATRO RODAS, 1969, n. 110, p. 7).

Com o mesmo motor que o Jeep Willys, levando até 6 pessoas, o Aero nacional ainda tinha semelhanças ao modelo 55 americano e segundo a Revista Quatro Rodas, (1960, n. 3, p. 68), o Aero-Willys não teria modificações para 1961. (ver Figura 1).

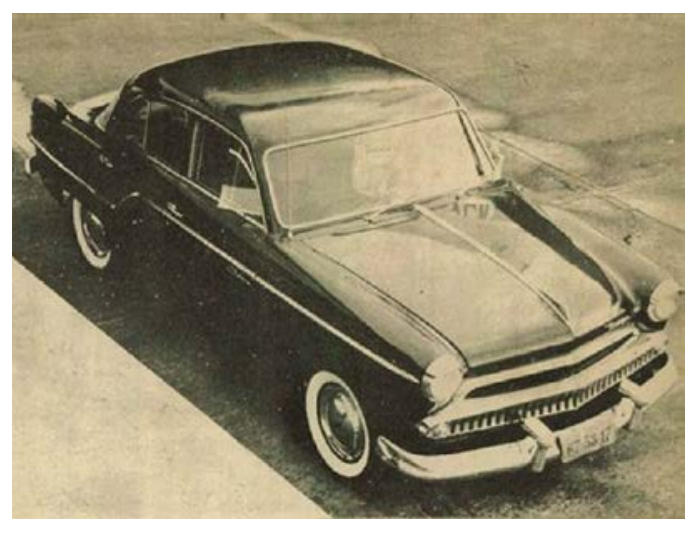

Figura 1 - Aero Willys.

Fonte: Revista Quatro Rodas, edição de setembro de 1960, p. 9.

Percebe-se no decorrer do texto que mesmo após o lançamento, os veículos passavam por um processo de melhoria contínua para adequação urgente ao mercado e condições brasileiras. Em 1962 é lançado o Aero Willys 1962 ainda guardando bastante semelhança com o modelo 1960, mas com algumas modificações como frisos, acabamentos interiores, novo sistema de freios, entre outras. Essas adaptações já tinham sido trabalhadas no Brasil. (ver Figura 2). 


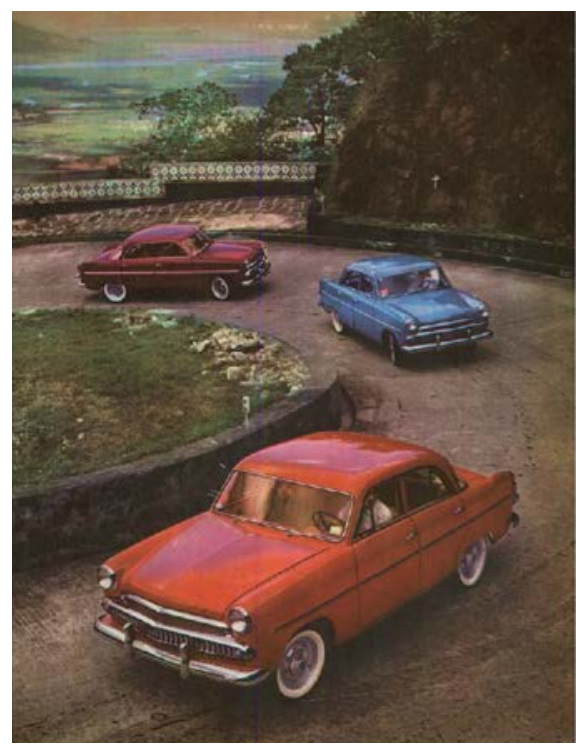

Figura 2 - Aero-Willys 1962. com algum nível de nacionalização, como citado acima. Fonte: Revista Quatro Rodas de fevereiro de 1962, p. 77.

Em 1963, é lançado o Aero 2600 (inicialmente denominado Projeto 213 ) ${ }^{1}$ já redesenhado por "estilistas brasileiros". Posteriormente o motor do Jeep foi substituído (1967) por não ser tão apropriado a um veículo de luxo.

Em Dezembro de 1962, vemos um informe publicitário sobre o Willys 2600 enfatizando como ser um veículo para as condições brasileiras. (Ver Figura 3)

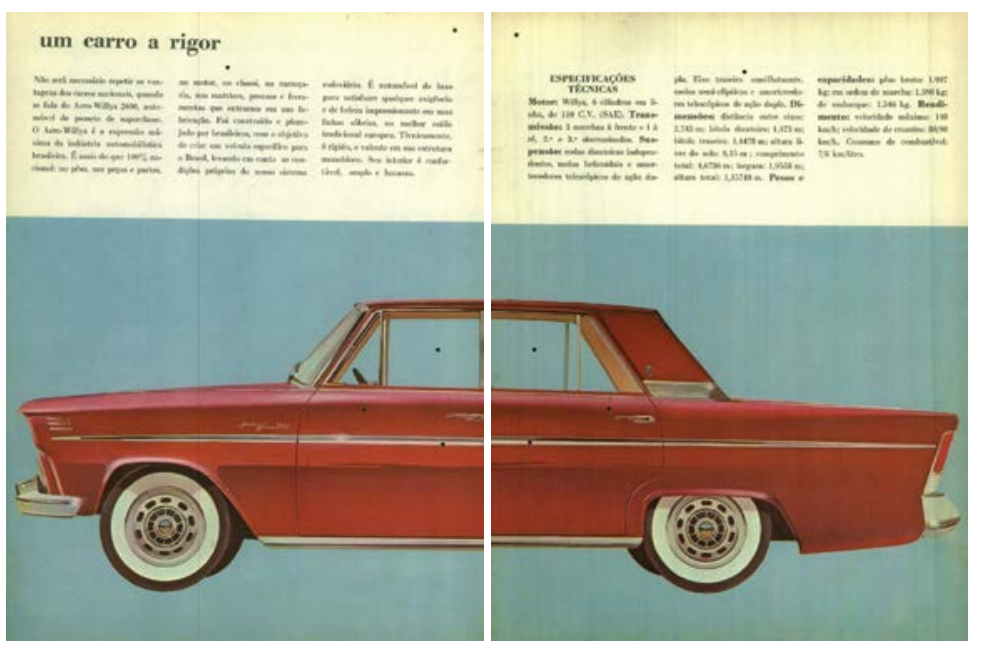

Figura 3 - Aero-Willys 2600.

Fonte: Revista Quatro Rodas de dezembro de 1962, p. 66 - 67.

Este veículo foi considerado o primeiro a ser "concebido e construído" no Brasil, o que envolveu grande sentimento de que podíamos fazer "o carro nacional", sob o ponto de vista do projeto: "Foi em 1961 que a diretoria da Willys Overland

${ }^{1}$ O Projeto 213 foi concebido inicialmente por Brook Steves, estilista da Willys, em 1957. "Passou a vir ao Brasil uma vez por ano, a partir de 1959, para acompanhar projetos as serem desenvolvidos no Brasil" (PIANCASTELLI apud ONO, 2002, p. 159 - 160). 
tomou a decisão: O Aero Willys 1963 seria um carro inteiramente novo, com estilo próprio e linha inédita no catálogo internacional." (RIBEIRO, 1962, n. 27, p. 80).

O ano de 1963 marcava 60 anos do lançamento de primeiro veículo Willys, então era importante marcar esta data. Sua fabricação começou ainda em outubro de 1962. Cabe reforçar a informação que o projeto teve 129.403 horas regulares de trabalho, e 43.508 horas extra, no período de fevereiro de 1961 a julho de 1962. (Cf. RIBEIRO, Hamilton. Automóvel é nosso, 1962, n. 27. p. 83)

Sobre o resultado dos incentivos à instalação de fábricas automobilísticas no $A B C$ paulista Fiori $(2006$, n. 556, p. 162-164) soube sintetizar algumas características sobre o mercado automotivo na década de 1960:

- os incentivos fiscais para a instalação de fábricas no $A B C$ paulista, como Volkswagen, Mercedes-Benz e a própria Willys Overland. O Brasil era o nono produtor mundial com 183.721 unidades em 1963.

- houve um superdimensionamento entre a produção e a demanda do consumidor. A própria Willys registra em 1964 produção de 46\% inferior à sua capacidade de produção.

- "não contribuiu para um melhor desempenho nas vendas o fato das fábricas terem optado por importar de suas matrizes equipamentos e ferramental de modelos já ultrapassados em seus países de origem", o que refletiu diretamente no Willys de 1960. (FIORI, 2006, n. 556, p. 162 - 164)

Em 1965, a Willys lança uma versão de luxo, o Itamaraty, nome sugerido por Mauro Salles, que era jornalista especializado da área e que naquele momento foi importante para a publicidade de automóveis no Brasil. ${ }^{2}$

Houve ainda o lançamento do Aero 1967 com mudanças pouco significativas e, a Willys ainda lança o Itamaraty Executivo com mudanças mais expressivas, como frente, calotas, lanternas e acabamento, mas sem grandes resultados perante seus concorrentes. A seguir vemos uma foto com os principais modelos produzidos pela Willys durante sua atuação no Brasil. (ver Figura 4).

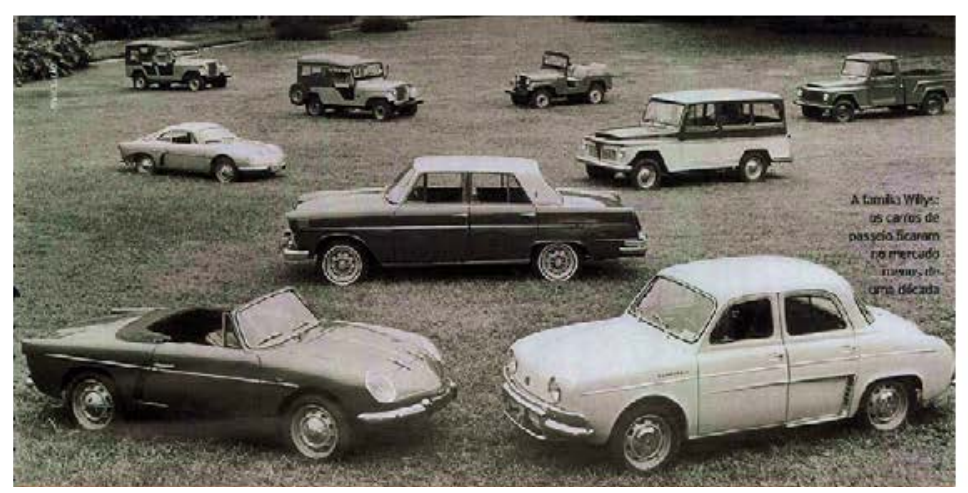

Figura 4 - Modelos Willys.

Fonte: Revista Quatro Rodas de setembro de 2006, p. 163. Podemos observar modelos como Jeep, mais ao fundo na foto, o modelo Rural Pick Up e Perua (no fundo à direita).

\footnotetext{
2 Sobre. "Mauro Salles: Inventou a publicidade e o marketing de carros no Brasil. Em 1966, convenceu o presidente da Willys, Max Pearce, de que o nome Aero-Willys Luxo era ruim. Pela sugestão "Itamaraty", pediu a conta publicitária da Willys. Também jornalista, foi durante oito anos um dos colunistas de QUATRO RODAS." Quatro Rodas, agosto de 2010, p. 170.
} 
A Willys estava em 4o lugar em vendas e nesta época as companhias maiores começaram a adquirir companhias menores. A Ford, então, assume o controle majoritário das ações da Willys Overland, e em 1969, o nome passa a ser Ford-Willys do Brasil S.A.

\section{DA IMPLANTAÇÃO E IMPORTÂNCIA DO DEPARTAMENTO DE ESTILO E A FIGURA DE ROBERTO MAURO ARAÚJO.}

Em 1962, segundo reportagem de Hamilton Ribeiro, na Revista Quatro Rodas de outubro, há um relato bastante completo das atividades do então Departamento de Estilo da Willys Overland.

Nesta reportagem de 14 páginas, intitulada "Automóvel também é nosso" (RIBEIRO, 1962), vemos o relato das atividades do departamento no desenvolvimento de novos veículos ou soluções e trata do lançamento do Aero Willys-63.

Uma grande surpresa é ver que em sua primeira página, a foto é a de Roberto Araújo, mostrando uma valorização desse funcionário, e de sua atividade. Hoje é muito comum a atividade de Design ficar generalizada para a própria empresa e aqui temos este exemplo de mostrar o responsável pelo departamento em uma imagem que enfatiza seu poder de criação: "E surgiu o primeiro carro concebido no Brasil, para demonstrar que automóvel também é nosso." (RIBEIRO, 1962, n. 10, p. 80). (ver Figura 5).

"Desde o início do projeto, em 1961, era um desafio proposto pela diretoria da Willys Overland, onde este deveria ser um carro completamente novo, com "estilo" próprio e linha inédita no catálogo internacional". Diz-se ainda de "suas linhas determinadas com liberdade de criação pelo Departamento de Estilo da emprêsa (grafia do original)." (RIBEIRO, 1962, n. 3, p. 80).

O carro foi apresentado no Salão do Automóvel de Paris, em outubro de 1962, sendo o "primeiro concebido e construído num país da América Latina". O veículo ainda foi apresentado no III Salão do Automóvel de São Paulo em janeiro de 1963.

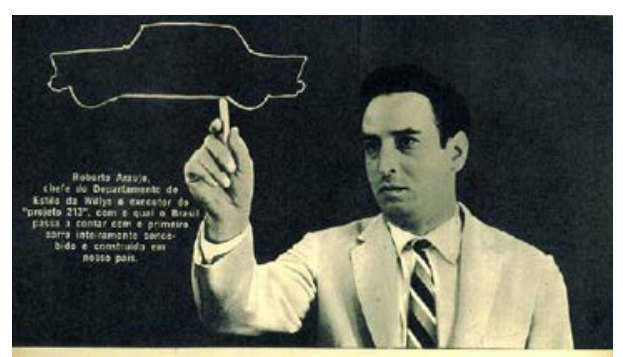

Aero Willys-63, da idéia no papel à linha de montagem

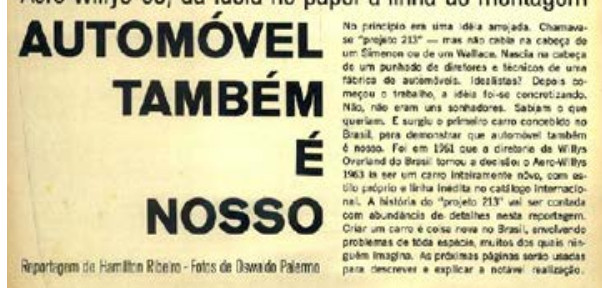

Figura 5 - Roberto Araújo em foto para a reportagem "Automóvel também é nosso". Fonte: Revista Quatro Rodas, outubro de 1962, p. 80. Foto de Oswaldo Palermo. 
É um carro pioneiramente desenvolvido para nossas condições geográficas, econômicas e sociais. Foi um complexo esforço para conseguir concretizar este projeto de redesenho. Aí vemos mais um indício de valorização do líder de seu Departamento de Estilo, com seu esforço em trabalhar durante o dia e estudar Arquitetura à noite, com, naquele momento, 29 anos.

Neste momento o Departamento de Estilo só tinha 2 funcionários (Roberto Mauro Araújo e o desenhista Valter da Cunha Brito). Havia somente uma pequena sala e passaria a ocupar o prédio 10 da fábrica. Em fevereiro de 1963, o Departamento contava com 3 desenhistas, 8 modeladores, 2 técnicos em estofamento e pintura, uma secretária e um zelador. O prédio que no início era muito grande, já se tornara cheio. (Cf. RIBEIRO, Hamilton, Automóvel é nosso, n.27, p. 93). (ver Figura 6).

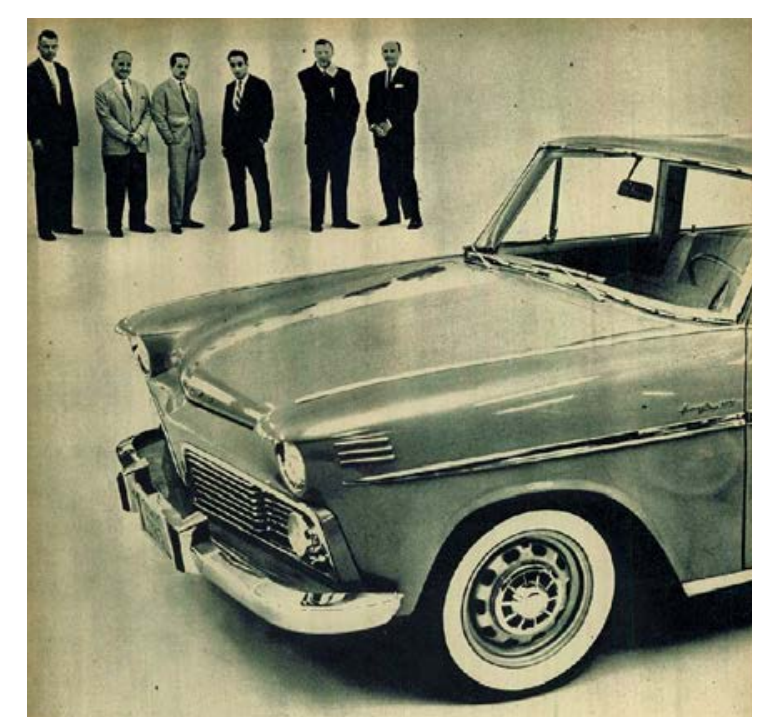

Figura 6 - Equipe da Willys. A partir da esquerda, Eric Manitzsch, engenheiro de chassis; Milton Ludwiger, gerente da engenharia de Carroçaria; Marcos de Mello, engenheiro projetista; Roberto Araújo, chefe do Departamento de Estilo; Frank Erdman, chefe da Divisão de Engenharia de Produção e Willian Max Pearce, diretor-superintendente da Willys Overland no Brasil.

Fonte: Revista Quatro Rodas de outubro de 1962, p. 93.

Imaginou-se no princípio dessa pesquisa, que Roberto Araújo, defendia as atividades do Departamento de Estilo supostamente sozinho. Porém, havia um apoio da Direção da empresa ao projeto. Ainda na reportagem encontramos vários adjetivos entusiastas durante a explicação do processo de desenvolvimento de um novo veículo, uma maneira enfática de valorizar um trabalho árduo e que muitos não sabem que existe. O sentimento do envolvimento de todos ainda pode ser notado na reportagem de janeiro de 1966, onde é relatado o desejo de Willian Max Pearce, diretor da Willys Overland, em fazer um carro popular que deveria ser "muito barato" e mais uma vez, desenvolvido no Brasil.

O modelo de 1962 teve modificações estéticas guardando sua característica de carro compacto.

"Relativamente alto e curto, tem um aspecto maciço, ainda mais realçado pelo corte abrupto do extremo posterior e pelas saliências dos pára-lamas traseiros. O perfil lateral do 62 tem uma aparência mais alongada graças principalmente ao friso cromado reto que se estende 
por quase todo o comprimento do carro. As novas rodas e calotas cumprem bem sua finalidade de ventilar os novos freios, embora pareçam um tanto leves." (QUATRO RODAS, 1962. n. 19, p. 76)

Outras modificações são citadas e até a continuidade da utilização de grandes áreas envidraçadas, ainda herança do modelo anterior, americano. Estas circunstâncias e características realçam a atividade de "Redesenho" do carro, adaptando e atualizando as formas, acessórios, comandos e acabamentos de maneira geral. Esta prática é realizada ainda hoje por montadoras, aproveitando por mais tempo os investimentos realizados para a implantação de um novo modelo.

Este processo de "Redesenho", denominada também como "facelift" citado por De Mitry ${ }^{3}$, (2014) também mostra a grande influência de Willian Max Pearce, que dirigia a Willys Overland no Brasil.

É possível perceber que dentro da Willys, o espírito era de sempre construir algo novo. Este sentimento era conjunto, iniciando com uma Diretoria que tinha essa preocupação constate e que se envolvia neste processo.

Segundo Eduardo Rugos, em entrevista a André Fiori, (2006, n. 556, p. 264), "Do jardineiro ao gerente-geral, todos os funcionários da empresa se viam com uma família". Este parece não estar se referindo necessariamente ao ambiente da Willys, mas esta frase confirma um sentimento que também é facilmente notado e expresso em entrevista com Antonio Adolfo De Mitry, um sentimento de envolvimento.

Antonio De Mitry atuou no Departamento de Estilo da Willys e a sua entrevista ajuda a levantar e confirmar aspectos interessantes citados até aqui.

"O Departamento de estilo estava iniciando... em 1958. eu entrei em 59, início de 59 e o meu querido amigo,... Roberto Mauro Araújo, é que chefiava o departamento. Então quando eu cheguei já existia o departamento, mas de uma forma assim... muito... com muito pouco gente trabalhando. Tinha só ele... ah... e um rapaz que cuidava de cores, que chamava Adolfo Zanella..."

Sobre a introdução da indústria automotiva e a consequente implantação do Departamento de Estilo, diz:

"A própria introdução da indústria automobilística americana no Brasil, uma das condições era a nacionalização dos itens, dos componentes, para que o Brasil desenvolvesse fábricas fornecedoras de indústria automobilística, perfis, chassis, rodas, eixos, mola, vela, peças para motor, peças para mecânica... sim... a indústria automobilística veio para o Brasil e precisou inovar e precisou expandir-se então lá na Willys tinha instruções para que eu procurasse fornecedores..."

\footnotetext{
3 Antonio De Mitry. Trabalhou na mesma equipe de Roberto Mauro Araújo.Foi Designer de interior de veículos, cuidando de materiais não metálicos. de desenvolvimento de bancos, laterais de porta, teto, tapetes e painel de instrumentos, fibra de coco moldado com látex. Desenvolvimento de fornecedores, promoções para o Departamento de Estilo e Gerência do Qualidade Antonio Adolfo De Mitry, É administrador de empresa de formação, mas construiu uma carreira como designer de Interior Trim (Acabamento de Interior), na Willys Overland, de 1959 a 1963. De seu currículo, em dezembro de 2014.
} 
"vou te contar que era um ambiente... eu preferia ficar na fábrica do que ficar em casa... porque era apaixonante, contaminante as motivações para nós arregaçarmos as mangas e modificar o painel de instrumento, por exemplo..."

Apesar de não termos como precisar uma data do início do Departamento de Estilo da Willys, aqui temos um data estimada desse início.

"... acho que o Roberto Araújo entrou em 57 na Willys para montar o departamento de estilo e ele era arquiteto, tinha taste, tinha gosto, combinações de proporcionalidade, decoração e cor, então ele deu um pincel, ele usou o pincel para colaborar no new look dos veículos.

"... então os departamentos de estilo foram pressionados a se desenvolverem e obviamente os fornecedores também tiveram que fazer departamentos de estilo dentro das suas fábricas, porque tinha que exe... apresentar projetos inéditos, novos, propostas, aceitavam bastante propostas dos fornecedores,..."

No depoimento de De Mitry também se identifica o impulso que a indústria automotiva teve, pois com o estabelecimento do Departamento de Estilo, os fornecedores também tiveram que se estruturar, primeiramente para atender as demandas que as montadoras solicitavam, mas também para começar a sugerir coisas, como cores, como o próprio depoente cita.

\section{DO HISTÓRICO DA FORD NO BRASIL E A AQUISIÇÃO DA WYLLIS OVERLAND 1919 -} 1969

Abrangemos aqui um breve e sucinto histórico da Ford, somente para localizar em que momento há a aquisição do Willys-Overland e um primeiro momento de interação entre as duas montadoras. A fonte principal desta trajetória foi o próprio site da montadora no Brasil onde há uma seção de histórico.

Em 16 de junho de 1903 é fundada em Detroit a Ford Motor Company e é apresentado em seguida o 1 o automóvel Ford, o Modelo A.

"1919

... A criação da filial brasileira é aprovada pela diretoria da Ford Motor Company,... estabeleceu o início das operações com apenas 12 funcionários num depósito de 2 andares na rua Florêncio de Abreu, no centro de São Paulo, onde se iniciou a montagem de automóveis Modelo T e caminhões Ford TT."

\section{“1957}

Em 26 de agosto, o 1o veículo Ford brasileiro, o caminhão F-600 V8 a gasolina, deixa a linha de montagem da fábrica do Ipiranga. Com 40\% de nacionalização, ainda tinha motor importado. Em outubro daquele ano foi produzida a primeira pick-up F-100 nacional. 


\section{7}

... a Ford produzia seu primeiro automóvel brasileiro, o Galaxie 500, com o motor V8 de 4,5 litros produzido no Brasil. O carro foi apresentado ao público em 2 de abril daquele ano e foi o primeiro automóvel verdadeiramente moderno feito no Brasil. Já em outubro, a Ford adquire o controle acionário de Willys-Overland do Brasil..." (Site Ford do Brasil S.A., 2014).

Em 1967, a Ford passou a ser denominada Ford-Willys, momento que houve aproximação da Ford com o pessoal da Willys, período em que a Ford ainda preservaria alguns veículos da mesma, mas aos poucos os descontinuaria.

Ainda segundo Móra, em entrevista a Claudio Habara, diz:

"E quando o Corcel chegou. 'abafou'. As reações da mídia e do público foram surpreendentes porque era um carro moderno e atualizado, que trazia muita esperança de desenvolvimento para setor"

\section{“1969}

É apresentado ao público o Ford Corcel, veículo destinado ao mercado de carros médios, derivado de projeto da Willys-Overland que recebeu centenas de aperfeiçoamentos. É até hoje o automóvel de maior produção na história da Ford brasileira." (Site Ford do Brasil S.A., 2014).

Vemos aqui uma publicidade da fase em que a Ford-Willys promove sua linha Willys, com o teor de que a entrada da Ford era uma das inovações da empresa. (ver Figura 7).

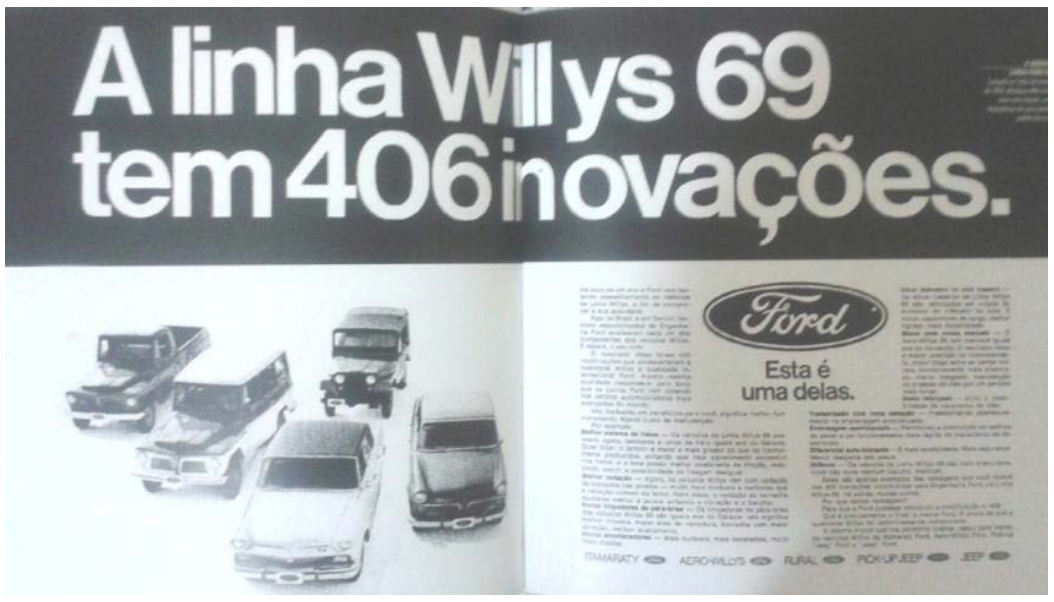

Figura 7 - Publicidade da Ford-Willys.

Fonte: Revista Quatro Rodas de dezembro de 1968, sem número de página.

Em 1971, a Ford acaba por descontinuar a linha Willys.

Percebe-se em todo esse relato que a Ford ainda aproveitou algumas iniciativas oriundas da Willys, mas aos poucos mostrou sua posição de dominante até o estabelecimento novamente de nome Ford do Brasil S. A. 


\section{CONCLUSÕES}

Enfim resumimos abaixo os aspectos mais relevantes da Willys e do Departamento de Estilo que contribuem para a História do Design na Indústria Automotiva no Brasil.

- lança o possível primeiro carro $100 \%$ nacional (de produção e projeto), o Aero-Willys 2600;

- inicia, ao que tudo indica, o primeiro Departamento de Estilo nas montadoras estabelecidas no Brasil; mesmo que sem precisão da data, ocorre aproximadamente em 1957/1958.

- com suas atividades, "força" de alguma maneira que seus fornecedores também comecem a abrir ou iniciar atividades ligadas ao chamado Departamento de 'Estilo'. Embora a dimensão que isto pode ter alcançado em outras empresas não possa aqui ser medida com exatidão, uma vez que não fazia parte dos objetivos deste trabalho.

- a participação no desenvolvimento do Corcel. Seu projeto (M) teve início com a equipe brasileira da Willys e mesmo com a aquisição pela Ford e as modificações, o projeto foi concretizado e veio a ser o carro mais vendido pela Ford do Brasil na época.

- a passagem de Roberto Araújo, gerenciando esse Departamento, sua presença no estabelecimento dessa atividade dentro da Willys e posteriormente da Ford, confirmam seu espírito empreendedor e sua importância na história da indústria automotiva no Brasil, aqui retratada de modo resumido. Araújo foi reconhecido na época pelo campo do Design uma vez que foi convidado para palestrar sobre Departamento de Estilos em indústrias em evento organizado pela Associação Brasileira de Desenho Industrial, ABDI, em novembro de 1964, (ABDI, 1965: p.19). Desse modo, sua trajetória pessoal merece uma pesquisa posterior mais profunda.

Algumas reflexões gerais ainda podem ser colocadas como discussão sobre o Desenvolvimento de Produto, como:

- a cópia ainda é uma prática em alguns ramos de nosso setor fabril e registrar uma iniciativa como esta desfaz a crença de que a atividade de projeto próprio com qualidade por parte de brasileiros é mais antiga do que se pensa, mesmo na área de design automotivo.

- outro ponto que podemos destacar é a importância do Desenvolvimento de Produto, primeiro como um propulsor da economia e também como desenvolvimento de capacidade projetual de um país. O caso analisado aqui ocorreu como resultado indireto de uma política desenvolvimentista de Juscelino Kubistchek (1956 - 1960, período na presidência do país) que visava inicialmente o aumento de produção industrial com grande entrada de capital estrangeiro. Mas foi um momento que não só neste setor, mas em outros, alguns brasileiros aproveitaram para tentar militar no projeto e não apenas na produção. Em meio à entrada de recursos estrangeiros, houve espaço para um sentimento nacionalista que incentivou agentes locais e que teve em alguns casos, apoios de estrangeiros como no caso posterior do automóvel Brasília da Vokswagen. Mesmo dentro da Willys, a figura de Max Pierce também apóia o desenvolvimento de produto. Alguns depoimentos relatados ainda nos oferecem exemplos do envolvimento interno dos funcionários para com o compromisso de desenvolver, todos embalados pelo otimismo da época e com as metas de produção a serem atingidas, crendo no desenvolvimento econômico do país. 
- um segundo ponto é que o Desenvolvimento de Produto não é feito por um, nem somente um departamento. Necessita-se de todo um ambiente para este ocorra, e mesmo quando o iniciamos de maneira isolada há um momento em que o trabalho só vinga com apoio coletivo de diferentes frentes dentro de uma organização.

- O estabelecimento do campo do Design no Brasil, no período referido ainda nos fornece dados interessantes como de que forma se deu a participação de profissionais brasileiros em montadoras instaladas aqui. Estudos como esse podem contribuir para averiguar como essas montadoras e indústrias estrangeiras em geral se posicionaram diante de designers locais e as suas decisões, e os seus motivos, para investir localmente em projeto uma vez que possuíam projetos em suas matrizes. Em que níveis o projeto externo foi adaptado as condições brasileiras e de que forma isso foi feito e qual teria sido a resposta do mercado brasileiro para um produto fabricado aqui, mas desenvolvido por inteiro lá fora? Ou ainda como projetos estrangeiros foram adaptados para as condições brasileiras? Estas são algumas das questões que este trabalho nos instigou ao seu final para futuras pesquisas.

Temos certeza de que a pequena contribuição que este texto traz, auxilia uma identidade para os profissionais brasileiros que trabalharam e trabalham com design de veículos no país e no exterior desde ao menos os anos 1980. História e raízes em um campo profissional são elementos da construção social de uma identidade profissional e a de designer de veículos, apesar dos percalços e fim de iniciativas como a da Gurgel, vem sendo construída paulatinamente e com muito esforço desde que Roberto Araújo e sua equipe lançaram, conforme nossas referências, o "primeiro carro $100 \%$ nacional".

\section{REFERÊNCIAS}

ABDI. PRODUTO E LINGUAGEM. São Paulo: ABDI. v. 1, n. 1, primeiro trimestre. 1965.

ALBERTI, V. Manual da História Oral. Rio de Janeiro: FGV, 2005

BARROS, José D' Assunção. "Sobre a feitura da micro-história". Revista OPSIS, vol. 7, no 9, p. 167-185, 2007.

CARDOSO, Rafael. O advento da produção em massa. In: Uma introdução à história do Design. 3 ed. 2 reimp., São Paulo, Blucher, 2008. Cap.4, p. 109 - 117.

CARLOS, Luis. Breve História do Erro Willys. Disponível em:

$<$ http://carroslokoscarros.blogspot.com.br/2012/11/breve-historia-do-aerowillys.html>. Acesso em: 30 dez. 2014.

CIVITA, Roberto (ed). Palácio sobre rodas. Revista Quatro Rodas. São Paulo, n. 544, p. 40, out. 2005.

Pessoas que puseram as coisas nos eixos nos últimos 50 anos. Revista Quatro Rodas. São Paulo, n. 607, p. 128-154, 170, aug. 2010.

CIVITA, Victor (ed.). Estes são os carros do Brasil. Revista Quatro Rodas. São Paulo, n. 2, p. 6-11, set. 1960. set. 1960.

Estes são os carros do Brasil. Revista Quatro Rodas. São Paulo, n. 2, p. 6-11, 
. Salão foi mais salão. Revista Quatro Rodas. São Paulo, n. 2, p. 26-27, set. 1960.

. Estilismo brasileiro começa bem. Revista Quatro Rodas. São Paulo, n. 2, p. 2829, set. 1960. 1961. . É um carro lindíssimo. Revista Quatro Rodas. São Paulo, n. 9, p. 61-62, abr. Os homens que constroem automóveis. Revista Quatro Rodas. São Paulo, n. 12, p. 20-27, jul. 1961.

. Aero-Willys. Revista Quatro Rodas. São Paulo, n. 19, p. 76-89, fev. 1962.

Aero-Willys com carimbo internacional. Revista Quatro Rodas. São Paulo, n. 29, p. 66-67, dez. 1962.

Willys quer carro popular. Revista Quatro Rodas. São Paulo, n. 66, p. 70-71, jan. 1966.

Corcel vem a galope. Revista Quatro Rodas. São Paulo, n. 93, p. 20, abr. 1968. Coleção Digital Quatro Rodas.

. A linha Willys 69 tem 406 inovações. Revista Quatro Rodas. São Paulo, n. 101, sem número de página, dez. 1968.

CURCIO, Gustavo; MUYLAERT, Marília. Antonio A. De Mitry: na prática, a teoria é outra. SENAI-SP Editora. 2014.

FIORI, André. Contra o relógio. Revista Quatro Rodas. São Paulo, n. 556, p. 162 - 165. set. 2006.

HABARA, Claudio. Biografia do automóvel brasileiro: o design das multinacionais. Tempo \$ Memória, 2006.

NASCIMENTO, Paulo César do. A História do automóvel no Brasil: arte e evolução. Editora Komedi, São Paulo, 2011.

ONO, Maristela Mitssuko. Contextualização histórica dos setores automobilístico, moveleiro e de eletrodomésticos do Brasil. Tese de Doutorado. São Paulo: FAU/USP, 2006.

PENNA, José Roberto; SOLARI, Jean; VASSÃO, Nehemias. A guerra começou... Revista Quatro Rodas. São Paulo, n. 66, p. 50-55, jan. 1966.

RIBEIRO, Hamilton. Automóvel é nosso. Revista Quatro Rodas, São Paulo, 1962, n. 27, p. 80 - 93.

SALLES, Mauro. Veja lá em cima o oval, Mr. Salles. Revista Quatro Rodas. São Paulo, n. 518, p. 30. set. 2003.

SEVERINO, Antônio Joaquim. Metodologia do trabalho científico. Cortez. 23 ed. rev. ampl. 2007.

VASSÃO, Nehemias. Histórias Secretas. Revista Quatro Rodas. São Paulo, n. 556. p. 178-179, jun. 2006. 
Ford do Brasil S.A. Disponível em <http://www.ford.com.br/sobre-a-ford/historia>. Acesso em: 06 dez. 2014.

Biblioteca Digital da Redarte. Disponível em:

<http://docvirt.com/docreader.net/DocReader.aspx?bib=Bib_Redarte\&PagFis=2142>. Acesso em: 06 dez. 2014.

VEIGA, Edison. 2012. Um registro dos primeiros carros que circularam em São Paulo. Disponível em: <http://sao-paulo.estadao.com.br/blogs/edison-veiga/foto-historicafamilia-santos-dumont-a-bordo-dos-primeiros-carros-de-sp/>. Acesso em: 08/12/2014. WIKIPEDIA. Aero Willys. Disponível em: < https://pt.wikipedia.org/wiki/Aero_Willys>. Acesso em: 22 mai. 2016.

\section{FONTES}

ROCHA, Ari Antonio da. Conversa realizada em 3 de novembro de 2014 e por telefone em 01 de dezembro de 2014.

PIRES, Auresnede Stephan. Consulta por e-mail realizada em 07 /12/ 2014.

DE MITRY, Antonio Adolfo. Entrevista concedida em 15 de dezembro de 2014, na cidade de São Paulo, com 55 minutos de duração. 